\title{
Further observations on the gastric secretory depressant in human gastric juice
}

\author{
PETER B. ROWE, BARBARA H. FENTON, AND DEBORAH BEESTON \\ From the Unit of Clinical Investigation and Wellcome Laboratories, \\ the Royal North Shore Hospital of Sydney, Crows Nest, N.S.W., Australia
}

EDITORIAL SYNOPSIS A gastric secretory depressant 'gastrone' has been previously found in normal gastric juice. These studies show that it is present in the neutralized gastric juice and is not destroyed by peptic digestion in one hour, indicating that this factor is not a protein and would be consistent with the view that it is related to the mucopolysaccharides in gastric juice.

The presence of a gastric secretory depressant in human gastric juice has been confirmed by many workers since it was first described by Brunschwig, Van Prohaska, Clarke, and Kandel in 1939. Twenty-four years later it still has not been identified although Glass (1962) believes that it is related to the mucosubstances in gastric juice and is predominantly carbohydrate in nature.

Brunschwig, Clarke, Van Prohaska, and Schmitz (1941) originally made the observation that this depressant factor, or 'gastrone' as it was labelled by Code, was present in higher concentration in patients with histamine-fast achlorhydria. Other workers, including Blackburn, Code, Chance, and Gambill (1950) and Katzka (1962), agree with this although Menguy and Smith (1960) failed to confirm it and criticize the dose schedule employed by earlier workers.

If the observation is correct then it is feasible that the decreased concentration of inhibitory factor in acid gastric juice might be due to peptic digestion and consequent loss of activity.

The object of this study was to assess whether or not this was in fact the case, by comparing the gastric secretory depressant effect of gastric juice collected under conditions of continuous intragastric neutralization with the same gastric juice after it had undergone peptic digestion.

\section{METHODS}

Human gastric juice was collected from a wide group of patients including patients free of gastro-intestinal disease, gastric and duodenal ulcer patients, patients with pernicious anaemia, and patients with gastric carcinoma, employing Kay's augmented histamine test. During the test, however, the gastric juice was con- tinuously kept to $p H \mathbf{H} .0$ to 8.5 using $2.5 \mathrm{~g} . \%$ sodium bicarbonate solution in order to prevent peptic digestion. The juice was dialysed continuously against distilled water, freeze-dried, and pooled so that any one pool would contain up to 30 individual specimens. The pools each contained specimens from each group of patients and were similar in constitution.

One half of each pool was retained for use as such and was known as 'neutralized gastric juice'. The other half was dissolved in distilled water, the $p \mathrm{H}$ reduced to 2 with $0 \cdot 1 \mathrm{~N}$ hydrochloric acid incubated for one hour at $37 \cdot 4^{\circ} \mathrm{C}$. This solution was brought to $\mathrm{pH} 7$ with sodium bicarbonate, redialysed, and freeze-dried. This preparation was known as 'acid-incubated gastric juice'.

The fact that peptic digestion occurs in this condition of incubation was demonstrated by using the technique of Piper (1960) and secondly by carrying out electrophoresis before and after acid incubation when the albumin peak in the neutralized gastric juice was split up into a series of smaller peaks.

Immediately before use these freeze-dried preparations were dissolved in normal saline and the concentration adjusted so that a protein content of $15 \mathrm{mg} . / \mathrm{ml}$. of solution was attained.

The intravenous dose for each rat was calculated on the basis of $0.1 \mathrm{ml} . / 100 \mathrm{~g}$. rat weight.

To assess the effect of these two preparations on gastric secretion we employed the Shay rat preparation described by Shay, Sun, and Gruenstein (1954). The test preparation and normal saline control injections were given via the jugular vein immediately before ligation of the pylorus and four hours before removal of the stomach.

The stomachs were opened and their contents analysed for volume, $p \mathrm{H}$, and free acid content. The gastric mucosa was then carefully inspected for the presence of ulcers or haemorrhages.

In preliminary work we satisfied ourselves that we could satisfactorily demonstrate gastric suppression with ordinary human gastric juice using this technique. 


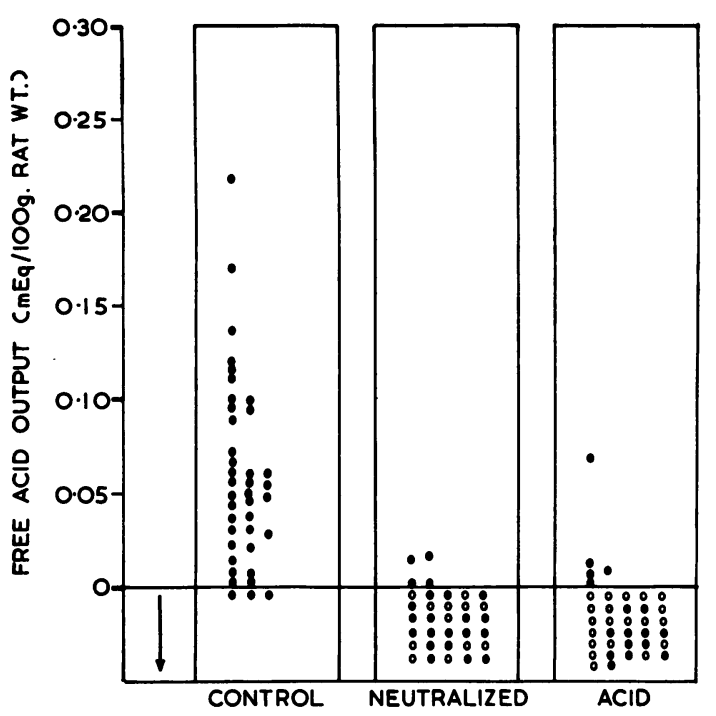

FIG. 1. Free acid output per 100 g. rat weight. Each point represents one test animal.

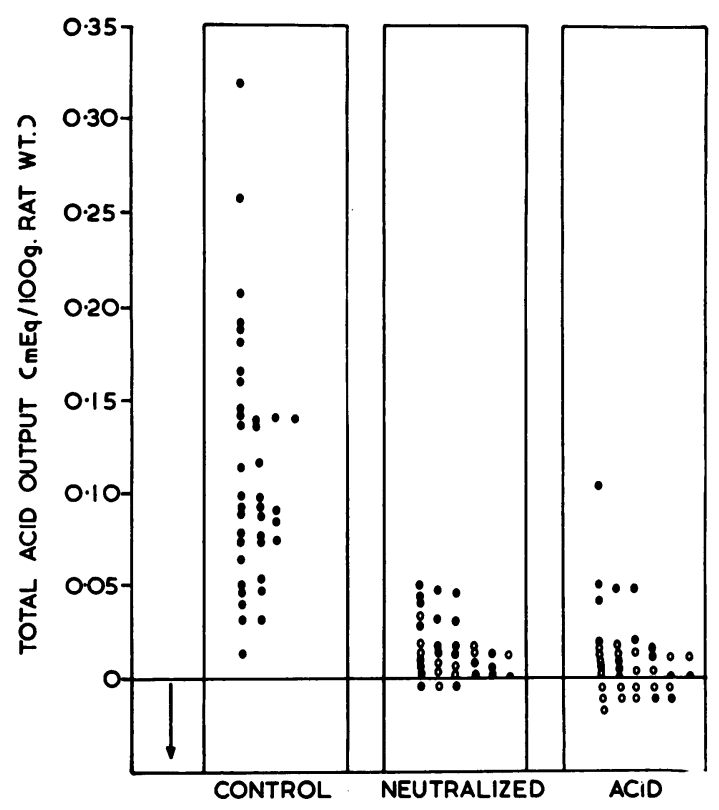

FIG. 2. Total acid output per $100 \mathrm{~g}$. rat weight. Each point represents one test animal.

Control = normal saline

Neutralized = 'neutralized gastric juice'

Acid = 'acid gastric juice'

Hollow points (0) represent blood-stained specimens. All values below the horizontal line are zero readings.
In any test period three groups of rats were tested:1 With normal saline; 2 with neutralized gastric juice; and 3 with acid-incubated gastric juice. The test rats were randomized with the controls from the point of view of time sequence of testing.

\section{RESULTS}

In assessing the results, we rejected all tests with blood-stained gastric contents in order to exclude any buffering effect on the acid secretion. All animals with faeces or excessive debris in their stomach were excluded at the outset.

The acid secretion over the four-hour period was calculated on the basis of free acid output per $100 \mathrm{~g}$. rat weight. The results of this are shown in Figures 1 and 2.

These results were statistically analysed employing a non-parametric analytical technique ( $\mathrm{X}^{2}$ test) and revealed:- 1 That compared with the controls there was significant depression of free acid secretion $(P<0.001)$ with the neutralized gastric juice. 2 That these findings were identical in the acidincubated gastric juice test group compared with the controls. 3 That there was no difference between the degree of suppression of free acid secretion obtained with either of the gastric juice preparations (P $>0.3)$, i.e., peptic digestion neither depressed nor enhanced the inhibitory factor.

\section{DISCUSSION}

The results show that 'gastrone' is present in the neutralized gastric juice and that its activity is not destroyed by peptic digestion for one hour. This suggests that this material is not primarily protein in nature and would be consistent with the observation of Glass (1962) that it is a P.A.S.-staining, predominantly carbohydrate material.

In assessing the results of the study from a different point of view it is of interest to consider the theory offered by Menguy and Smith (1960) that if gastrone is a physiological material in man its release should be stimulated by a low antral $p \mathrm{H}$. In our study, however, we obtained gastric juice with a high inhibitory activity despite continuous intragastric neutralization, i.e., a high antral $p \mathrm{H}$. Admittedly, however, we did not compare the relative gastrone content with and without gastric neutralization.

Dr. D. W. Piper and Dr. P. E. Baume were responsible for the instigation of this project. Their assistance and advice was greatly appreciated. 


\section{REFERENCES}

Blackburn, C. M., Code, C. F., Chance, D. P., and Gambill, E. E. (1950). Confirmation of presence of a gastric secretory depressant in gastric juice of humans. Proc. Soc. exp. Biol. (N.Y.), 74, 233-236.

Brunschwig, A., Clarke, T. H., Van Prohaska, J., and Schmitz, R. (1941). A gastric secretory depressant in extracts of achlorhydric carcinomatous stomachs. Ann. Surg., 113, 41-46.

_, Van Prohaska, J., Clarke, T. H., and Kandel, E. V. (1939). A secretory depressant in gastric juice of patients with pernicious anemia. J. clin. Invest., 18, 415-422.
Glass, G. B. J. (1962). Biologically active materials related to gastric mucus in the normal and in the diseased stomach of man. Gastroenterology, 43, 310-325.

Katzka, I. (1962). A gastric secretory inhibitor in normal and pernicious anemia. Ibid., 43, 71-74.

Menguy, R., and Smith, W. O. (1960). Inhibition of gastric secretion in the rat by normal and abnormal human gastric juice. Proc. Soc. exp. Biol. (N.Y.), 105, 238-239.

Piper, D. W. (1960). The estimation of peptic activity in gastric juice using radioiodinated serum albumin as substrate. Gastroenterology, 38, 616-621.

Shay, H., Sun, D. C. H., and Gruenstein, M. (1954). A quantitative method for measuring spontaneous gastric secretion in the rat. Gastroenterology, 26, 906-913. 